\title{
Potencial agrícola de um composto organomineral à base de resíduo de sisal, esterco e farinha de rocha para produção de mudas de sisal
}

Agricultural potential of organic compost produced based on sisal residue, manure and rock flour in the production of sisal seedlings

\author{
C. da S.Sousa ${ }^{1 *}$; D.C. dos Prazeres ${ }^{2}$; I. N. dos Santos ${ }^{2}$; F.S. Lima ${ }^{1}$; A.C.F.Soares ${ }^{2}$ \\ IInstituto Federal de Educação, Ciência e Tecnologia Baiano - Campus Uruçuca, 45.680-00, Uruçuca-Bahia, Brasil
}

${ }^{2}$ Centro de Ciências Agrárias, Ambientais e Biológicas, Universidade Federal do Recôncavo da Bahia-Campus Cruz das Almas, 45.400-00, Cruz das Almas-Bahia, Brasil

*Autor correspondente: cssagro@yahoo.com.br

(Recebido em 23 de maio de 2015; aceito em 05 de janeiro de 2016)

\begin{abstract}
O sisal é uma cultura de grande importância socioeconômica para a Bahia, contudo, ainda pouco estudada, tornando-se necessárias pesquisas que apontem alternativas tecnológicas para a produção de mudas com boa qualidade fitossanitária e nutricional. O aproveitamento do resíduo gerado do desfibramento das folhas é uma alternativa viável para adubação dos plantios. O presente trabalho avaliou o potencial agrícola de um composto produzido com diferentes proporções de resíduo de sisal, farinha de rocha e esterco no crescimento e nutrição de mudas de sisal. Os experimentos foram conduzidos no delineamento em blocos ao acaso, esquema fatorial $5 \times 5$, sendo 5 compostos organominerais e 5 doses $\left(0,10,20,30\right.$ e $\left.50 \mathrm{t} \mathrm{ha}^{-1}\right)$, com cinco repetições. Não foi possível definir a melhor dose a ser aplicada dos compostos organominerais, entretanto, de um modo geral, estes foram superiores ao tratamento controle (dose zero sem aplicação de composto organomineral) em promover melhoria nutricional nas mudas de sisal. O composto C5 com $30 \%$ esterco $+30 \%$ farinha de rocha $+40 \%$ resíduo de sisal promoveu aumentos significativos na altura das plantas $(38,9 \%$ e $45 \%)$, diâmetro do caule $(15,6 \%$ e $61,1 \%)$ e produção biomassa (50\% e $78 \%)$ respectivamente nas mudas de sisal cultivadas em solo argiloso e arenoso, respetivamente. Fatores como tipo e grau de fertilidade do solo, ciclo vegetativo da cultura, bem como, material a ser utilizado devem ser considerados no preparo do composto organomineral.

Palavras-chave: Agave sisalana, produção de mudas, composto organomineral.
\end{abstract}

Sisal is a great socio-economic importance of culture in Bahia, however, still little studied, becoming necessary studies that show alternative technologies for the production of seedlings with good plant health and nutritional quality. The use of the shredding of the leaves generated waste is a viable alternative for fertilization of crops. This study evaluated the agricultural potential of a compound produced with different proportions of sisal waste, rock flour and manure on growth and nutrition of sisal seedlings. The experiment was conducted in randomized block design in factorial design $2 \times 5 \times 5,2$ soils, 5 organic compounds and 5 doses $\left(0,10,20,30\right.$ and $\left.50 \mathrm{tha}^{-1}\right)$, with four replications. Unable to define the optimal dose to be applied from organo compounds, however, generally, these were superior to the control (zero dose without applying organic-compound) to promote improvement in nutritional sisal seedlings. The compound C5 with manure $30 \%+30 \%$ + rock flour $40 \%$ sisal residue led to significant increases in plant height (38.9\% and $45 \%)$, diameter (15.6\% and $61.1 \%)$ and biomass production (50\% and $78 \%)$ respectively in sisal seedlings grown in a clay soil and sandy, respectively. Factors such as type and degree of soil fertility, plant vegetative cycle, as well as material to be used should be considered in the preparation of the organic compound.

Keyworks: Agave sisalana, seedling production, organo compounds. 


\section{INTRODUÇÃO}

O sisal é uma cultura de grande importância socioeconômica para o Estado da Bahia, promovendo geração de emprego e renda, e a desconcentração espacial do PIB com a exportação das fibras e de outros produtos. A atuação de importantes atores e articuladores envolvidos na atividade sisaleira contribui para a geração de diversos subprodutos, possibilitando a abertura de novos mercados e o aumento da capacidade de venda da produção [1].

As fibras naturais do sisal extrapolaram sua utilização tradicional como fio para amarrar fardo de feno, material para embalagens, tapetes e mantas. Hoje, elas se combinam com as fibras sintéticas na fabricação de móveis diversos, na confecção de painéis automobilísticos, nas indústrias náutica e aeronáutica e até na substituição do cimento amianto, até então utilizado para fabricar telhas, paredes e caixas d'água [2].

Entretanto, a cultura do sisal é muito pouco estudada, tornando-se necessárias pesquisas que apontem alternativas tecnológicas para manejo adequado do plantio e produção de mudas de boa qualidade fitossanitária e nutricional. Na literatura, existem poucas informações sobre a recomendação de adubação para a cultura do sisal e as informações existentes são muito antigas, como as recomendações de adubação e calagem para a cultura do sisal no Estado da Bahia e os sistemas de manejo para essa cultura também são descritos de forma muito generalizada [3].

Embora o esterco seja o principal adubo organomineral utilizado na região semiárida, a quantidade produzida nas propriedades é insuficiente, capaz de adubar apenas $12 \%$ das áreas agrícolas nesta região [4]. Além disso, o esterco disponível nas propriedades rurais é de baixa qualidade, com baixo teor de nitrogênio e alto teor de lignina, resultando em imobilização de $\mathrm{N}$ do solo, consequentemente, comprometendo o desenvolvimento das culturas agrícolas $[5,6]$.

$\mathrm{Na}$ região produtora de sisal no Estado da Bahia, uma alternativa para complementar a adubação das culturas, seria o reaproveitamento do resíduo resultante do processo de desfibramento da folha de sisal, uma vez que apenas $4 \%$ da folha corresponde a fibra, sendo o restante transformado em resíduo. Os agricultores usam uma parte muito pequena desse resíduo, sem tratamento adequado, na adubação dos plantios de sisal e na alimentação de caprinos e ovinos. Esse resíduo e o esterco são aplicados sem qualquer critério, com relação ao tratamento adequado, qualidade e quantidade aplicada no solo.

A produção de um composto organomineral utilizando o resíduo de sisal, esterco e enriquecido com farinha de rocha natural, apresenta-se como uma alternativa viável para obtenção de um adubo organomineral de boa qualidade para uso agrícola nessas regiões. O resíduo de sisal e o esterco são materiais de baixo custo e fácil aquisição nas propriedades rurais. A farinha de rocha possui alto teor de $\mathrm{SiO}_{2}$ total (em torno de $60 \%$ ), que apesar de não ser um nutriente, vem sendo bastante estudado como alternativa para auxiliar na absorção de outros nutrientes. Além de ser benéfico para a nutrição mineral, também vêm sendo realizados diversos estudos sobre o efeito do silício no controle de doenças de plantas $[7,8,9]$. O presente trabalho teve como objetivo avaliar o potencial de compostos organominerais produzidos com diferentes proporções de resíduo de sisal, farinha de rocha natural e esterco no crescimento e nutrição de mudas de sisal.

\section{MATERIAL E MÉTODOS}

\section{1 - Produção dos compostos organominerais}

Foram coletados resíduos provenientes do desfibramento de folhas de sisal e esterco de caprino em propriedades rurais localizadas na região sisaleira da Bahia para serem utilizados no preparo dos compostos organominerais. O resíduo do sisal, farinha de rocha e esterco foram misturados em diferentes proporções (v/v) de modo a completar $100 \mathrm{~L}$, totalizando nove pilhas de compostagem, conforme demonstrado na Tabela 1.

As pilhas do material organomineral para compostagem foram dispostas em uma configuração geométrica cônica. O processo de compostagem foi o de reviramento ou "Windrow", considerado simples e eficiente para a estabilização do material organomineral. Na fase de degradação ativa do material organomineral, o reviramento foi realizado manualmente a cada três dias, durante os primeiros 30 dias, seguindo-se um reviramento a cada seis dias, por mais 30 dias. Durante a fase de reviramento foram introduzidas sondas no interior de cada pilha, na base, no centro e no topo, para a determinação da temperatura, diariamente, com uso de um termômetro digital. A umidade do material foi monitorada com a retirada de amostras semanais e secagem em estufa a $65^{\circ} \mathrm{C}$, por 
$48 \mathrm{~h}$, seguida de secagem a $105^{\circ} \mathrm{C}$, até massa constante. A umidade do material foi mantida no máximo a $55 \%$.

Tabela 1. Composição dos compostos organominerais.

\begin{tabular}{cc}
\hline $\begin{array}{c}\text { Composto } \\
\text { organomineral }\end{array}$ & Composição \\
\hline C1 & 10 L Esterco + 10 L Farinha de Rocha + 80 L Resíduo de Sisal \\
C2 & 10 L Esterco + 20 L Farinha de Rocha + 70 L Resíduo de Sisal \\
C3 & 20 L Esterco + 10 L Farinha de Rocha + 70 L Resíduo de Sisal \\
C4 & 20 L Esterco + 20 L Farinha de Rocha + 60 L Resíduo de Sisal \\
C5 & 30 L Esterco + 30 L Farinha de Rocha + 40 L Resíduo de Sisal \\
\hline
\end{tabular}

$\mathrm{Na}$ fase de maturação, o material organomineral permaneceu sem reviramento por 30 dias, estando pronto para uso agrícola após este período. Amostras dos compostos foram coletadas no final do período de compostagem, para caracterização química, conforme apresentado na Tabela 2.

Tabela 2. Caracterização química dos compostos organominerais.

\begin{tabular}{|c|c|c|c|c|c|}
\hline Determinações & C1 & C2 & $\mathbf{C 3}$ & C4 & C5 \\
\hline pH em CaCl2 0,01M & 9,1 & 9,0 & 8,7 & 8,7 & 8,2 \\
\hline Densidade $\left(\mathrm{g} \mathrm{cm}^{-3}\right)$ & 0,50 & 0,58 & 0,60 & 0,59 & 0,79 \\
\hline Umidade perdida a $60-65^{\circ} \mathrm{C}(\%)$ & 3,20 & 2,12 & 1,64 & 1,63 & 1,68 \\
\hline $\begin{array}{l}\text { Umidade perdida entre } 65 \text { e } \\
110^{\circ} \mathrm{C}(\%)\end{array}$ & 2,02 & 3,34 & 2,99 & 2,29 & 1,88 \\
\hline Umidade total (\%) & 5,22 & 5,14 & 4,63 & 3,92 & 3,54 \\
\hline Inertes & 0,00 & 0,00 & 0,00 & 0,00 & 0,00 \\
\hline M.O. total (\%) & 22,8 & 19,34 & 17,05 & 12,38 & 8,73 \\
\hline M.O. compostável (\%) & 18,28 & 15,84 & 13,27 & 9,56 & 6,37 \\
\hline $\begin{array}{l}\text { M.O. resistente a compostagem } \\
(\%)\end{array}$ & 4,52 & 3,50 & 3,78 & 2,79 & 2,36 \\
\hline $\begin{array}{l}\mathrm{C} \text { total (organomineral e } \\
\text { mineral \%) }\end{array}$ & 12,67 & 10,75 & 9,47 & 6,86 & 4,85 \\
\hline C organomineral (\%) & 10,16 & 8,80 & 7,37 & 5,31 & 3,54 \\
\hline Resíduo mineral total (\%) & 71,98 & 75,20 & 78,32 & 83,83 & 87,73 \\
\hline Resíduo mineral insolúvel (\%) & 53,30 & 58,02 & 64,56 & 70,06 & 74,87 \\
\hline Resíduo mineral solúvel (\%) & 18,68 & 17,18 & 13,76 & 13,67 & 12,86 \\
\hline $\mathrm{N}$ total $(\%)$ & 1,15 & 0,99 & 0,59 & 0,56 & 0,58 \\
\hline$P$ total $(\%)$ & 2,42 & 2,49 & 2,78 & 2,88 & 3,01 \\
\hline $\mathbf{K}(\%)$ & 1,84 & 2,35 & 1,47 & 1,57 & 1,08 \\
\hline Ca total $(\%)$ & 7,06 & 5,54 & 4,91 & 4,39 & 3,95 \\
\hline Mg total (\%) & 1,79 & 1,58 & 1,33 & 1,22 & 0,90 \\
\hline$S$ total $(\%)$ & 0,21 & 0,07 & 0,37 & 0,28 & 0,20 \\
\hline Relação C/N (C total e $\mathbf{N}$ total) & $11 / 1$ & $11 / 1$ & $16 / 1$ & $12 / 1$ & $8 / 1$ \\
\hline $\begin{array}{l}\text { Relação C/N (C organomineral e } \\
\text { N total) }\end{array}$ & $9 / 1$ & $9 / 1$ & $12 / 1$ & $9 / 1$ & $6 / 1$ \\
\hline $\mathrm{Cu}$ total $\left(\mathrm{mg} \mathrm{kg}^{-1}\right)$ & 46 & 49 & 42 & 49 & 62 \\
\hline Mn total $\left(\mathrm{mg} \mathrm{kg}^{-1}\right)$ & 496 & 413 & 369 & 568 & 538 \\
\hline Zn total $\left(\mathrm{mg} \mathrm{kg}^{-1}\right)$ & 75 & 90 & 69 & 66 & 71 \\
\hline Fe total $\left(\mathrm{mg} \mathrm{kg}^{-1}\right)$ & 12672 & 13692 & 14402 & 15732 & 19367 \\
\hline B total $\left(\mathrm{mg} \mathrm{kg}^{-1}\right)$ & 10 & 5 & 5 & 5 & 4 \\
\hline Na total $\left(\mathrm{mg} \mathrm{kg}^{-1}\right)$ & 2467 & 3032 & 2507 & 2360 & 1819 \\
\hline
\end{tabular}




\section{2 - Instalação dos experimentos}

Foram instalados dois experimentos em casa de vegetação, em delineamento de blocos ao acaso com 5 repetições, esquema fatorial 5 x 5 , sendo 5 compostos organominerais e 5 doses $(0$, $10,20,30$ e $\left.50 \mathrm{t} \mathrm{ha}^{-1}\right)$.

Os solos utilizados no experimento foram coletados na camada $0-20 \mathrm{~cm}$ de profundidade em áreas produtoras de sisal na região semiárida da Bahia, e em seguida, foram secos ao ar, homogeneizados e peneirados (peneira com malha de $2 \mathrm{~mm}$ ). Subamostras dos solos foram coletadas para caracterização química e física [10], conforme resultados apresentados na Tabela 3.

Os solos foram acondicionados em vasos com capacidade para $3 \mathrm{~kg}$, realizada a incorporação dos compostos organominerais nas doses $10,20,30$ e $50 \mathrm{t} \mathrm{ha}^{-1}$, que em seguida, foram incubados por 30 dias. Após este período de incubação, foi realizado o plantio de uma muda de sisal/vaso.

Tabela 3. Caracterização química e física dos solos utilizado no experimento.

\begin{tabular}{|c|c|c|}
\hline \multirow[t]{2}{*}{ Característica } & \multicolumn{2}{|c|}{ Valor } \\
\hline & Argiloso & Arenoso \\
\hline $\operatorname{Areia}\left(\mathrm{g} \mathrm{kg}^{-1}\right)$ & 399 & 788 \\
\hline Silte $\left(\mathrm{g} \mathrm{kg}^{-1}\right)$ & 336 & 162 \\
\hline $\operatorname{Argila}\left(\mathrm{g} \mathrm{kg}^{-1}\right)$ & 265 & 50 \\
\hline $\mathrm{pH}\left(\mathrm{H}_{2} \mathrm{O}\right)$ & 6,9 & 5,5 \\
\hline $\mathbf{P}\left(\mathbf{m g} / \mathbf{d m}^{3}\right)$ & 110 & 25 \\
\hline $\mathbf{K}^{+}\left(\mathbf{c m o l}_{\mathbf{c}} \mathbf{d m}^{-3}\right)$ & 0,56 & 0,19 \\
\hline $\mathrm{Ca}^{+2}\left(\mathrm{cmol}_{\mathrm{c}} \mathrm{dm}^{3}\right)$ & 10,6 & 1,60 \\
\hline $\operatorname{Mg}^{+2}\left(\mathrm{cmol}_{\mathrm{c} .} \mathrm{kg}^{-1}\right)$ & 3,70 & 0,60 \\
\hline $\mathrm{Ca}^{+2}+\mathrm{Mg}^{+2}\left(\mathrm{cmol}_{\mathrm{c}} \mathbf{d m}^{-3}\right)$ & 14,30 & 2,20 \\
\hline $\mathrm{Na}^{+}\left(\mathrm{cmol}_{\mathrm{c}} \mathbf{d m}^{-3}\right)$ & 0,0 & 0,1 \\
\hline $\mathrm{Al}^{+++}\left(\mathrm{cmol}_{\mathrm{c}} \mathbf{d m}^{-3}\right)$ & 0,33 & 0,03 \\
\hline $\mathrm{H}^{+}+\mathrm{Al}^{+3}\left(\mathrm{cmol}_{\mathrm{c}} \mathrm{dm}^{-3}\right)$ & 1,21 & 2,86 \\
\hline$S\left(\operatorname{cmol}_{\mathbf{c}} \mathbf{d m}^{-3}\right)$ & 15,20 & 2,43 \\
\hline CTC $\left(\mathrm{cmol}_{\mathrm{c}} \mathrm{dm}^{-3}\right)$ & 16,41 & 5,29 \\
\hline $\mathrm{V}(\%)$ & 93 & 46 \\
\hline Matéria orgânica $\left(\mathrm{g} \mathrm{kg}^{-1}\right)$ & 8,28 & 6,73 \\
\hline
\end{tabular}

\section{4 - Avaliação do estado nutricional e crescimento das mudas de sisal}

Após 120 dias, foi realizada coleta do experimento, sendo inicialmente determinada a altura das mudas com auxílio de uma régua milimetrada e diâmetro do caule com auxílio de um paquímetro digital. Em seguida, as mudas de sisal foram coletadas, separando-se parte aérea e raízes, sendo o material vegetal acondicionado em sacos de papel e transferido para estufa de ventilação forçada a $65^{\circ} \mathrm{C}$ até atingir peso constante. Após seco, o material vegetal foi pesado para determinação da produção de biomassa seca, moído em moinho tipo Wiley, e mineralizado através de digestão com ácido sulfúrico e peróxido de hidrogênio [11]. Nos extratos obtidos após mineralização do material vegetal, foram determinados os teores de $\mathrm{N}$ pelo método de Kjeldahl e $\mathrm{P}$ por colorimetria.

\section{5 - Análise estatística}

Os resultados obtidos foram submetidos à análise de variância e teste de Scott \& Knott a 5\% de probabilidade, para a comparação das médias, utilizando o programa estatístico SISVAR.

\section{RESULTADOS E DISCUSSÃO}

Na Tabela 4, são apresentados os resultados da análise de variância para altura das plantas, diâmetro do caule, produção de biomassa e teor de $\mathrm{N}$ e $\mathrm{P}$ na parte aérea das mudas cultivadas em solo argiloso e arenoso, após aplicação de doses crescentes dos compostos organominerais. Não 
houve efeito da interação sobre a altura das plantas, diâmetro do caule e produção de biomassa da parte aérea das mudas cultivadas em ambos os solos. É possível perceber que no experimento realizado utilizando solo argiloso, os teores de $\mathrm{N}$ e $\mathrm{P}$ na biomassa aérea das plantas foram influenciados pelo efeito da interação D x C (dose x composto) ao nível de $1 \%$ de probabilidade. A interação estudada $\mathrm{D}$ x C (dose $\mathrm{x}$ composto) também foi significativa sobre os teores de $\mathrm{N}$ e $\mathrm{P}$ $(\mathrm{P}<0,01)$ para as mudas de sisal cultivadas em solo arenoso. Houve efeito dos compostos sobre a altura das plantas, diâmetro do caule, produção de biomassa e teores de $\mathrm{N}$ e $\mathrm{P}(\mathrm{P}<0,1 \%)$.

Tabela 4. Resumo da análise de variância geral (quadrados médios) para as variáveis altura das mudas $(A L T)$, diâmetro do caule (DC), produção de biomassa seca (BS), teor de $N$ na parte aérea $(T N)$ e teor de $P$ na parte aérea $(T P)$ em função das doses de compostos organominerais em dois experimentos utilizando solo argiloso e arenoso.

\begin{tabular}{|c|c|c|c|c|c|c|}
\hline \multicolumn{7}{|c|}{ Experimento 1 - Solo argiloso } \\
\hline \multirow{2}{*}{$\begin{array}{l}\text { Fontes de } \\
\text { variação }\end{array}$} & \multirow[t]{2}{*}{ GL } & \multicolumn{5}{|c|}{ Quadrado médio } \\
\hline & & ALT & DC & BS & TN & TP \\
\hline Bloco & 3 & $2,535^{\text {ns }}$ & $0,028^{\text {ns }}$ & $0,263^{\mathrm{ns}}$ & $997,617^{\text {ns }}$ & $2,652^{\text {ns }}$ \\
\hline $\begin{array}{c}\text { Composto } \\
\text { (C) }\end{array}$ & 4 & $30,621^{* *}$ & $0,253^{* *}$ & $41,702^{* * *}$ & $81752,533^{* * *}$ & $96,434^{* * *}$ \\
\hline Dose (D) & 4 & $0,383^{\text {ns }}$ & $0,042^{\mathrm{ns}}$ & $1,736^{\mathrm{ns}}$ & $10458,957^{* *}$ & $25,184^{* * *}$ \\
\hline D x C & 16 & $3,924^{\text {ns }}$ & $0,109^{\text {ns }}$ & $3,002^{\text {ns }}$ & $8654,078^{* * * *}$ & $13,694^{* * *}$ \\
\hline Erro & 72 & 4,844 & 0,062 & 2,044 & 2539,179 & 1,188 \\
\hline Média geral & - & 8,75 & 2,10 & 8,08 & 219,28 & 8,76 \\
\hline CV $(\%)$ & - & 25,14 & 11,91 & 17,68 & 22,98 & 12,44 \\
\hline \multicolumn{7}{|c|}{ Experimento 2 - Solo arenoso } \\
\hline \multirow{2}{*}{$\begin{array}{l}\text { Fontes de } \\
\text { variação }\end{array}$} & \multirow[t]{2}{*}{ GL } & \multicolumn{5}{|c|}{ Quadrado médio } \\
\hline & & ALT & DC & BS & TN & TP \\
\hline Bloco & 3 & $3,749^{\text {ns }}$ & $0,355^{\mathrm{ns}}$ & $0,940^{\mathrm{ns}}$ & $82,692^{\mathrm{ns}}$ & $0,5890^{\mathrm{ns}}$ \\
\hline $\begin{array}{c}\text { Composto } \\
\text { (C) }\end{array}$ & 4 & $27,735^{* *}$ & $1,291^{\text {**** }}$ & $9,484^{* * *}$ & $4377,605^{* * *}$ & $3,446^{* * *}$ \\
\hline Dose (D) & 4 & $22,416^{\mathrm{ns}}$ & $0,175^{\mathrm{ns}}$ & $7,604^{\mathrm{ns}}$ & $13500,724^{* * * *}$ & $5,050^{* * *}$ \\
\hline D x C & 16 & $9,989^{\text {ns }}$ & $0,165^{\mathrm{ns}}$ & $1,104^{\mathrm{ns}}$ & $2752,779^{* * * *}$ & $2,066^{* * *}$ \\
\hline Erro & 72 & 7,710 & 0,152 & 0,864 & 268,830 & 0,334 \\
\hline Média geral & - & 7,31 & 1,50 & 2,67 & 88,81 & 2,34 \\
\hline CV $(\%)$ & - & 37,96 & 25,94 & 34,76 & 18,46 & 24,66 \\
\hline
\end{tabular}

O desdobramento da interação significativa $\mathrm{D}$ x C (dose $\mathrm{x}$ composto) sobre os teores de $\mathrm{N}$ e $\mathrm{P}$ na parte aérea das mudas de sisal, em ambos experimentos é apresentado na Tabela 5. No experimento onde foi utilizado solo argiloso, observa-se que doses crescentes do $\mathrm{C} 1$ promoveram efeito quadrático no teor de $\mathrm{N}$, onde as mudas apresentaram ponto mínimo de $141,4 \mathrm{~g}$ de N planta${ }^{1}$ com aplicação da dose $22,8 \mathrm{t} \mathrm{ha}^{-1}$. Doses crescentes dos compostos $\mathrm{C} 2 \mathrm{e} \mathrm{C} 4$ promoveram aumento linear no teor de $\mathrm{N}$ das mudas de sisal, sendo observado incremento de até $100 \%$ e 53,8\% em relação à dose controle, respectivamente. Não foi observado efeito significativo da aplicação das diferentes doses dos $\mathrm{C} 3$ e $\mathrm{C} 5$

No segundo experimento, onde as mudas foram cultivadas em solo arenoso, a aplicação de doses crescentes do $\mathrm{C} 1$ também resultou em efeito quadrático no teor de $\mathrm{N}$, sendo registrado um ponto mínimo de $81,3 \mathrm{~g}$ de $\mathrm{N}_{\text {planta }}{ }^{-1}$ com aplicação da dose 4,97 $\mathrm{t} \mathrm{ha}^{-1}$. Comportamento semelhante foi registrado com a aplicação das doses crescentes dos C2 e C3. A adubação das mudas com diferentes doses do $\mathrm{C} 5$, resultou em aumento linear no teor de $\mathrm{N}$ na parte aérea das mudas. A aplicação do $\mathrm{C} 4$ não proporcionou aumento significativo nos teores de $\mathrm{N}$ nas mudas de sisal 
Tabela 5. Equações de regressão para conteúdo de nutrientes na biomassa seca de mudas de sisal em resposta às doses crescentes de compostos organominerais.

\begin{tabular}{|c|c|c|c|}
\hline Solo & Composto* & Equação de regressão & $\mathbf{R}^{2}$ \\
\hline \multicolumn{4}{|c|}{ Experimento 1 - Solo argiloso } \\
\hline \multirow{5}{*}{$\mathbf{N}\left(\right.$ g planta $\left.^{-1}\right)$} & $\mathrm{C} 1$ & $\mathrm{Y}=252,9-9,77 \mathrm{X}+0,214 \mathrm{X}^{2 * * *}$ & 93,7 \\
\hline & $\mathrm{C} 2$ & $\mathrm{Y}=145,7+2,91 \mathrm{X}^{* *}$ & 83,4 \\
\hline & $\mathrm{C} 3$ & $Y=192,4$ & - \\
\hline & $\mathrm{C} 4$ & $\mathrm{Y}=255,3+2,75 \mathrm{X}^{* *}$ & 56,8 \\
\hline & $\mathrm{C} 5$ & $Y=159,0$ & - \\
\hline \multirow{5}{*}{$\mathbf{P}\left(\right.$ g planta $\left.^{-1}\right)$} & $\mathrm{C} 1$ & $\mathrm{Y}=9,736-0,032 \mathrm{X}+0,0029 \mathrm{X}^{2 * *}$ & 97,8 \\
\hline & $\mathrm{C} 2$ & $\mathrm{Y}=7,400+0,124 \mathrm{X} * * *$ & 77,6 \\
\hline & $\mathrm{C} 3$ & $\mathrm{Y}=6,095+0,287 \mathrm{X}-0,006 \mathrm{X}^{2 * * *}$ & 95,8 \\
\hline & $\mathrm{C} 4$ & $\mathrm{Y}=4,286-0,082 \mathrm{X}+0,003 \mathrm{X}^{2 * * *}$ & 78,6 \\
\hline & $\mathrm{C} 5$ & $Y=7,725+0,229 X-0,003 X^{2 * *}$ & 73,3 \\
\hline \multicolumn{4}{|c|}{ Experimento 2 - Solo arenoso } \\
\hline \multirow{5}{*}{$\mathbf{N}\left(\right.$ g planta $\left.^{-1}\right)$} & $\mathrm{C} 1$ & $\mathrm{Y}=89,237-3,19 \mathrm{X}+0,321 \mathrm{X}^{2 * * *}$ & 89,3 \\
\hline & $\mathrm{C} 2$ & $Y=81,736-1,394 X+0,055 X^{2 * * *}$ & 68,9 \\
\hline & $\mathrm{C} 3$ & $\mathrm{Y}=68,037+5,408 \mathrm{X}-0,096 \mathrm{X}^{2 * * *}$ & 79,3 \\
\hline & $\mathrm{C} 4$ & $Y=66,2$ & - \\
\hline & $\mathrm{C} 5$ & $\mathrm{Y}=58,088+1,392 \mathrm{X}^{* * *}$ & 78,4 \\
\hline \multirow{5}{*}{$\mathbf{P}\left(\right.$ g planta $\left.^{-1}\right)$} & $\mathrm{C} 1$ & $\mathrm{Y}=1,677-0,028 \mathrm{X}+0,001 \mathrm{X}^{2 * * *}$ & 91,9 \\
\hline & $\mathrm{C} 2$ & $Y=1,375-0,031 X$ & 82,8 \\
\hline & $\mathrm{C} 3$ & $\mathrm{Y}=1,753-0,030 \mathrm{X}$ & 58,5 \\
\hline & $\mathrm{C} 4$ & $Y=1,785$ & - \\
\hline & $\mathrm{C} 5$ & $Y=1,657+0,128 X-0,0016 X^{2 * *}$ & 88,9 \\
\hline
\end{tabular}

$* C 1=(10 \%$ esterco $+10 \%$ farinha de rocha $+80 \%$ resíduo de sisal $), C 2=(10 \%$ esterco $+20 \%$ de farinha de rocha $+70 \%$ resíduo de sisal $), C 3=(20 \%$ esterco $+10 \%$ farinha de rocha $+70 \%$ resíduo de sisal $)$, $C 4=(20 \%$ esterco $+20 \%$ farinha de rocha $+60 \%$ resíduo de sisal $)$ e C5 $=(30 \%$ esterco $+30 \%$ farinha de rocha $+40 \%$ resíduo de sisal).

Pode-se verificar efeito quadrático das doses do $\mathrm{C} 1$ sobre os teores de $\mathrm{P}$ nas mudas de sisal, com ponto de mínimo de 9,65 g de P planta ${ }^{-1}$ com a dose 5,52 $\mathrm{t} \mathrm{ha}^{-1}$ no solo argiloso e de 1,48 $\mathrm{g}$ de $\mathrm{P}$ planta ${ }^{-1}$ com a dose $14 \mathrm{t} \mathrm{ha}^{-1}$ no solo arenoso. Em ambos os solos, a aplicação de doses crescentes deste composto promoveram aumento de até $59,7 \%$ e $88,3 \%$ no teor de $\mathrm{P}$ nas mudas de sisal cultivadas em solo argiloso e arenoso, respectivamente, em relação à dose controle. No caso do $\mathrm{C} 2$, em ambos os solos, verifica-se que aplicação de doses crescentes promoveu incremento linear nos teores de $\mathrm{P}$ nas mudas de sisal. Observa-se que até a dose $50 \mathrm{t} \mathrm{ha}^{-1}$ deste composto, não foi possível determinar o ponto de máxima para o acúmulo deste nutriente em ambos os solos, sugerindo que doses superiores, poderiam continuar promovendo incremento de $\mathrm{P}$ nas mudas de sisal. No solo argiloso, os $\mathrm{C} 3$ e C4 apresentaram resposta quadrática sobre os teores de P nas mudas de sisal.

As mudas de sisal responderam positivamente às doses crescentes do $\mathrm{C} 5$, de modo que, melhores resultados foram obtidos com as doses 38,2 $\mathrm{t} \mathrm{ha}^{-1}$ (solo argiloso) e $40 \mathrm{t} \mathrm{ha}^{-1}$ (solo arenoso). A partir destas doses, em ambos os solos, houve tendência para redução do teor de $\mathrm{P}$ nas mudas. A aplicação do $\mathrm{C} 4$ no solo arenoso não teve efeito significativo sobre os teores de $\mathrm{P}$ na parte aérea das mudas de sisal.

De acordo com o resultado da análise de variância apresentado na Tabela 4, as características altura das plantas, diâmetro do caule e produção de biomassa não foram influenciadas $(\mathrm{P}>0,5)$ pela interação D x C (dose x composto). Contudo, pode-se verificar que houve efeito dos diferentes compostos sobre estas características, e portanto, os resultados são apresentados na Tabela 6, dos compostos organominerais independentemente da dose aplicada.

No experimento onde as mudas foram cultivadas em solo argiloso, observa-se que com relação à altura das plantas, o composto C5 apresentou os melhores resultados, diferindo estatisticamente dos demais. Maiores resultados proporcionados por este composto C5 também foram registrados nas mudas de sisal cultivadas em solo arenoso. Para o diâmetro do caule das mudas de sisal cultivadas no solo argiloso, o composto C5 apresentou as maiores médias. Os demais compostos não diferiram estatisticamente entre si. No solo arenoso, observou-se que o 
melhor composto foi o C5, seguido pelos compostos $\mathrm{C} 1$ e $\mathrm{C} 4$. Em ambos os solos, o composto C5, destacou-se em relação aos demais, promovendo aumento de $50 \%$ e $78 \%$ em relação ao composto C2 na produção de biomassa seca das mudas de sisal (Tabela 6).

Tabela 6. Altura, diâmetro do caule e produção de biomassa seca das mudas de sisal cultivadas em dois solos com compostos organominerais, independentemente da dose aplicada.

\begin{tabular}{cccc}
\hline Composto & $\begin{array}{c}\text { Altura das plantas } \\
(\mathbf{c m})\end{array}$ & $\begin{array}{c}\text { Diâmetro do caule } \\
(\mathbf{m m})\end{array}$ & $\begin{array}{c}\text { Biomassa seca da } \\
\text { planta }(\mathbf{g})\end{array}$ \\
\cline { 2 - 4 } & & Solo argiloso & \\
\hline $\mathbf{C 1}$ & $7,67 \mathrm{~b}$ & $2,09 \mathrm{~b}$ & $8,01 \mathrm{c}$ \\
$\mathbf{C 2}$ & $7,52 \mathrm{~b}$ & $1,98 \mathrm{~b}$ & $6,64 \mathrm{~d}$ \\
$\mathbf{C 3}$ & $8,62 \mathrm{~b}$ & $2,06 \mathrm{~b}$ & $6,75 \mathrm{~d}$ \\
$\mathbf{C 4}$ & $9,50 \mathrm{~b}$ & $2,10 \mathrm{~b}$ & $9,05 \mathrm{~b}$ \\
$\mathbf{C 5}$ & $10,45 \mathrm{a}$ & $2,29 \mathrm{a}$ & $9,96 \mathrm{a}$ \\
\hline $\mathbf{C V}(\%)$ & 25,14 & 11,91 & 17,68 \\
\hline $\mathbf{C 1}$ & & Solo arenoso & \\
\hline $\mathbf{C 2}$ & $6,0 \mathrm{~b}$ & $1,52 \mathrm{~b}$ & $2,35 \mathrm{c}$ \\
$\mathbf{C 3}$ & $6,17 \mathrm{~b}$ & $1,13 \mathrm{c}$ & $2,05 \mathrm{c}$ \\
$\mathbf{C 4}$ & $7,73 \mathrm{~b}$ & $1,43 \mathrm{c}$ & $2,20 \mathrm{c}$ \\
$\mathbf{C 5}$ & $7,97 \mathrm{~b}$ & $1,52 \mathrm{~b}$ & $3,15 \mathrm{~b}$ \\
$\mathbf{C V}(\%)$ & $8,70 \mathrm{a}$ & $1,82 \mathrm{a}$ & $3,65 \mathrm{a}$ \\
\hline
\end{tabular}

$* C 1=(10 \%$ esterco $+10 \%$ farinha de rocha $+80 \%$ resíduo de sisal $), C 2=(10 \%$ esterco $+20 \%$ de farinha de rocha $+70 \%$ resíduo de sisal $), C 3=(20 \%$ esterco $+10 \%$ farinha de rocha $+70 \%$ resíduo de sisal $)$, $C 4=(20 \%$ esterco $+20 \%$ farinha de rocha $+60 \%$ resíduo de sisal $)$ e $C 5=(30 \%$ esterco $+30 \%$ farinha de rocha $+40 \%$ resíduo de sisal).

Médias seguidas pela mesma letra nas colunas não diferem estatisticamente pelo teste de Scott \& Knott a $5 \%$ de probabilidade.

Observa-se de um modo geral, que a incorporação dos compostos organominerais produzidos à base de resíduo de sisal, esterco e farinha de rocha, independente da dose aplicada e em comparação à dose controle, promoveu melhorias significativas no crescimento e na nutrição das mudas de sisal. Estudos demonstraram resultados satisfatórios obtidos com a utilização de compostos organominerais, proporcionando melhoria na nutrição de plantas[12], fertilidade do solo[13] e produção de culturas de interesse econômico [14].

O emprego dos compostos organominerais para adubação também apresenta-se como uma alternativa viável do ponto de vista econômico e ambiental[15], uma vez que, é preparado com materiais de baixo custo e fácil aquisição pelos produtores rural da região. Adicionalmente, a produção dos compostos possibilita o reaproveitamento do resíduo que é gerado do desfibramento da folha de sisal, evitando que este material seja descartado inadequadamente no ambiente ou utilizado de forma inapropriada para adubação dos plantios.

A adubação utilizando compostos organominerais é uma alternativa promissora, para reposição da fertilidade do solo, principalmente para pequenos produtores rurais. Contudo, devese levar em consideração os tipos de materiais a serem utilizados no preparo do composto, suas proporções e condições do processo de compostagem, uma vez que isso influenciará na qualidade do composto produzido (teor de nutrientes, relação $\mathrm{C} / \mathrm{N}$ etc) e nos benefícios para o sistema de produção [16].

Além disso, as culturas apresentam diferenças quando às exigências nutricionais, e principalmente ao longo do ciclo vegetativo, o que torna necessário, identificar o material adequado para preparo do composto, de modo que a promover maior sincronização entre a disponibilização dos nutrientes de acordo com a demanda da cultura[17].

A fertilidade do solo também é um aspecto importante a ser considerado, pois a incorporação de composto organomineral produzido com materiais que apresentam alta relação $\mathrm{C} / \mathrm{N}$, pode resultar em imobilização dos nutrientes pelos micro-organismos do solo, reduzindo a disponibilidade destes para as plantas nos estágios iniciais de desenvolvimento[18]. 
Estudos futuros são necessários para avaliar outras proporções dos materiais utilizados no preparo dos compostos, bem como, doses e intervalo de adubação durante o processo de produção das mudas e desenvolvimento da cultura em campo. Tornam-se necessárias também pesquisas para avaliar o potencial agrícola destes compostos organominerais para adubação de outras culturas agrícolas de interesse econômico, principalmente da região, a exemplo da mandioca, feijão e milho, aumentando a produtividade e funcionando como uma alternativa para a reposição da fertilidade dos solos e dos nutrientes exportados por essas culturas no momento da colheita.

\section{CONCLUSÃO}

1. Não foi possível definir a melhor dose a ser aplicada dos compostos organominerais, entretanto, de um modo geral, estes foram superiores ao tratamento controle (dose zero sem aplicação de composto organomineral) em promover melhoria nutricional nas mudas de sisal;

2. Em ambos os solos, o composto C5 com $30 \%$ esterco $+30 \%$ farinha de rocha $+40 \%$ resíduo de sisal promove o crescimento das mudas de sisal.

\section{AGRADECIMENTOS}

Os autores agradecem à Capes pela concessão da bolsa de Pós-doutorado PNPD à Dra. Carla da Silva Sousa; ao CNPq pela concessão das bolsas de produtividade à Dra. Ana Cristina Fermino Soares, bolsa de iniciação científica ao graduando em Engenharia Agronômica Diego Cayres dos Prazeres e pela bolsa de Pos-doutorado Júnior ao Dr Francisco de Sousa Lima. Os autores agradecem também ao Dr. Tácio Oliveira Silva (in memoriam) pela elaboração do projeto.

\section{REFERÊNCIAS BIBLIOGRÁFICAS}

1. Silva ORRF, Beltrão NEM. (Ed.). O agronegócio do sisal no Brasil. $1^{\text {a }}$ ed. Brasília: Embrapa -SPI; Campina Grande: Embrapa- CNPA, 1999. 205 p.

2. Sindifibras. O projeto sisal-apex traz resultados positivos para asexportações baianas de sisal no primeiro trimestre do ano, que cresceramquase 40\%. Disponível em: 〈www.braziliansisal.com> Acesso em: 08 jun 2014.

2. Seagri. Secretaria de Agricultura do Estado da Bahia. Sisal. Disponível em: $<$ www.seagri.ba.gov.br/busca.asp $>$ page $=2 \& q a c t=s r c h \& r b p=10 \&$ keywords $=$ sisal $>$ Acesso: 25 ago 2014.

3. Garrido MS, Sampaio EVSB, Menezes RSC. Potencial de adubação orgânica com esterco no Nordeste do Brasil. $1^{a}$ ed. Recife: Ed. Universitária; 2008. Capítulo 5, Fertilidade do solo e produção de biomassa no semiárido; p. 123-140.

4. Silva TO, Menezes RSC. Adubação orgânica da batata com esterco e, ou, Crotalaria juncea. II Disponibilidade de N, P e K no solo ao longo do ciclo de cultivo. Rev Bras Ci Solo. 2007 JanFeb;31(1):51-61. http://dx.doi.org/10.1590/S0100-06832007000100006.

5. Menezes RSC, Salcedo IH. Mineralização de N após incorporação de adubos organominerais em um Neossolo Regolítico cultivado com milho. Rev Bras EngAgrícAmb. 2007 Jul-Ago; 11(4):361-367. http://dx.doi.org/10.1590/S1415-43662007000400003

6. Pozza AAA, Alves E, Pozza EA. Efeito do silício no controle da cercosporiose em três variedades de feijoeiro. Fitopatol Bras. 2004 Mar-Abr; 29(2): 185-188. http://dx.doi.org/10.1590/S010041582004000200010

7. Botelho DM, Pozza EA, Pozza AA. Intensidade da cercosporiose em mudas de cafeeiro em função de fontes e doses de silício. Fitopatol Bras. 2005 Dec;30(6):582-588, http://dx.doi.org/10.1590/S010041582005000600003

8. Moraes SRG, Pozza EA, Alves E, Pozza AAA. Efeito de fontes de silício na incidência e na severidade da antracnose do feijoeiro. Fitopatol Bras. 2006 Jan-Fev;31(1):6975.http://dx.doi.org/10.1590/S0100-41582006000100012

9. Embrapa - Empresa Brasileira de Pesquisa Agropecuária. Manual de análises químicas de solos, plantas e fertilizantes. Brasília: Embrapa Comunicação para Transferência de Tecnologia, 1999. 370p. 
10. Thomas RL, Sheard RW, Moyer JR. Comparison of conventional and automated procedure for nitrogen, phosphorus and potassium analysis of plant material using single digest. Agronomy J.1967 May; 59(1):240-243. doi:10.2134/agronj1967.00021962005900030010x

11. Dutra ED, Menezes RSC, Primo DC. Aproveitamento de biomassa residual agrícola para produção de compostos organominerais. Rev Bras Ci Agrár.2012 Nov;7(3):465-472. doi:10.5039/agraria.v7i3a1757

12. Oliveira LB, Accioly AMA, Nascimento CWA, Santos CLR, Flores RA, Barbosa FS. Estado nutricional e teores de metais pesados em plantas de alface adubadas com compostos organominerais. Biosci. J. 2014 Feb;30(1): 199-209.

13. Silva DJ, Mouco MAC, Gava, CAT, Giongo V, Pinto JM. Composto organomineral em mangueiras (Mangifera indica L.) cultivadas no semiárido do nordeste Brasileiro.Rev Bras Frutic. 2013 Set;35(3): 875-882. http://dx.doi.org/10.1590/s0100-29452013000300026

14. Figueiredo PG, Tanamati FY. Adubação orgânica e contaminação ambiental. Rev Verde Agro Des Sust. 2010 Jul-Set; 5(3): 01-04.

15. Jiménez Becker S, Ebrahimzadeh A, Plaza Herrada BM, Lao MT. Characterization of compost based on crop residues: changes in some chemical and physical properties of the soil after applying the compost as organic amendment. Com Soil Sci Plant Anal. 2010 Mar; 41(8): 696-708. doi:10.1080/00103620903563931

16. Menezes RSC, Sampaio EVSB, Silveira LM, Tiessen H, Salcedo IH. Produção de batatinha com incorporação de esterco e/ou crotalária no Agreste paraibano. 1ª ed. Rio de Janeiro:AS-PTA; 2002. Capítulo 3, Agricultura familiar e agroecologia no semi-árido: avanços a partir do agreste da Paraíba; p.261-270.

17. Vitti AC, Trivelin PCO, Gava GJC, Penatti CPP, Bologna IR, Faroni CE, Franco HCJ. Produtividade da cana-de-açúcar relacionada ao nitrogênio residual da adubação e do sistema radicular. Pesq. Agropec. Bras. 2007 Feb;42(2):249-256. http://dx.doi.org/10.1590/S0100-204X2007000200014 